CP, 2019, Vol.8 - No17, pp. 55/76 ISSN 2014-6752. Girona (Catalunya). Universitat de Girona. BRAVO, J.A.; MORA FERNÁNDEZ, J.; GALINDO ARRANZ, F. : Proaño como pionero de la Investigación Acción Participativa (IAP) en comunidades indígenas Recibido: 13/06/2019 - Aceptado: $15 / 12 / 2019$

\title{
Proaño como pionero de la Investigación Acción Participativa (IAP) en comunidades indígenas
}

\section{Proaño como pioneiro da Pesquisa-Ação Participativa (IAP) em comunidades indígenas}

\section{Proaño as a pioneer of Participatory Action Research (IAP) in indigenous communities}

\author{
Autores: \\ Julio Adolfo Bravo \\ Universidad Nacional de Chimborazo \\ Jorge Mora Fernández \\ Universidad Nacional de Chimborazo \\ Fermín Galindo Arranz \\ Universidade Santiago de Compostela
}

\section{Resumen}

Este artículo investiga y comprueba cómo el uso de las metodologías en la comunicación para el cambio social utilizadas por Leonidas Proaño en las comunidades indígenas de Chimborazo, Ecuador, le convierten en pionero en Latinoamérica en la utilización de la investigación acción participativa (IAP). Se empleó una metodología mixta, cualitativa y cuantitativa, a través del análisis y la revisión documental de la información contenida en los libros y actas de reuniones con organizaciones sociales y en 347 contenidos de las 94 ediciones de la revista Mensaje de 1954 a 1961, encontrando 153 actividades afines a la IAP.

Palabras clave: Investigación-Acción-Participativa IAP, derechos humanos, comunidades indígenas, Latinoamérica, comunicación y cambio social, edu-comunicación, alfabetización comunicativa, interculturalidad.

\section{Resumo}

Este artigo investiga e verifica como o uso de metodologias de comunicação para a mudança social usada por Leonidas Proaño nas comunidades indígenas de Chimborazo, Equador, faz dele um pioneiro na América Latina no uso da pesquisa-ação participativa (IAP). Utilizou-se uma metodologia mista, qualitativa e quantitativa, através da análise e revisão documental das informações contidas nos livros e atas de reuniões com organizações sociais e em 347 conteúdos das94ediçõesdarevista Mensajede1954a1961,encontrando-se153atividadesrelacionadasaolAP. Palavras-chave: Pesquisa participativa-ação IAP, direitos humanos, comunidades indígenas, América Latina, comunicação e mudança social, edu-comunicação, alfabetização comunicativa, interculturalidade. 


\section{Sumary:}

This article investigates and verifies how the use of communication methodologies for social change used by Leonidas Proaño in the indigenous communities of Chimborazo, Ecuador, makes him a pioneer in Latin America in the use of participatory action research (IAP). A mixed, qualitative and quantitative methodology was used, through the analysis and documentary review of the information contained in the books and minutes of meetings with social organizations and in 347 contents of the 94 editions of the magazine Mensaje from 1954 to 1961, finding 153 activities related to the IAP.

Keywords: Participatory-Action-Research IAP, human rights, indigenous communities, Latin America, communication and social change, edu-communication, communicative literacy, interculturality.

\section{Introducción}

Este artículo reflexiona sobre la utilización de la investigación acción participativa (IAP), por Leonidas Proaño, en las actividades desarrolladas para conseguir el cambio social frente a las injusticias y la marginación en las comunidades indígenas de la provincia de Chimborazo, ubicada a 183 kilómetros de Quito, capital de Ecuador.

La pregunta de investigación utilizada fue ¿de qué manera la investigación acción participativa de Proaño registró información sobre la realidad socio-cultural que sirvió para motivar la acción y cambio social de las comunidades indígenas de Chimborazo entre 1954 y 1988 ? El objetivo principal fue Identificar la utilización de la IAP en las comunidades de Chimborazo para transformación social. La metodología fue de tipo mixta: cualitativa y cuantitativa; como técnicas se utilizaron la revisión documental de libros y actas de reuniones dirigidas por Proaño; y el análisis de contenido de 94 ediciones de la revista Mensaje, órgano de difusión de la diócesis.

Con esta aproximación se buscó establecer cómo la IAP de Proaño sirvió de: 1. Investigación; 2. Acción, y 3. Participación; para que: a) se conociera la realidad de la diócesis de Riobamba; y, b) se elaborara el proyecto de acción con miras a la transformación integral del "hombre concreto" de Chimborazo. Así se pudo evidenciar cómo la metodología IAP, que desde el punto de vista científico coincide con el método católico ver-juzgar-actuar y con la teología de los signos de los tiempos, sirvió al Proaño científico para recuperar los valores humanos del indigenado, para que los "indios" tomen conciencia de su realidad social, política y económica, y para transformarla mediante procesos participativos. Cuestión que sirve recuperar como conocimiento científico - histórico para poder aplicarla a problemáticas socioculturales actuales, tales como la alfabetización intercultural digital para la conservación y difusión cultural en las comunidades indígenas del Chimborazo, Ecuador y Latinoamérica, dado que los modelos de Proaño también sirvieron en su época para emplearlos en otros países de la región que comprendieron que la resolución de sus problemas contribuía al cambio social.

Aunque los estudios indigenistas han ido incrementándose a través de las últimas décadas, Saldívar (2003) identifica el inicio de los estudios formales sobre este tema, en la década del noventa esa es, sin duda, la importancia que toma la vida de los pueblos indígenas en la política del estado. 
Ramón Máiz (2004, p. 130) estudió:

La emergencia de las movilizaciones indigenistas en América Latina durante los años ochenta y noventa del siglo xx, conjuntamente con un fenómeno político de primera magnitud para la democratización de los Estados latinoamericanos, constituye un notable desafío a la capacidad explicativa de la ciencia política.

Y, en Ecuador dice Ortiz (2011, p. 68):

La lucha del movimiento indígena en las últimas décadas se desarrolla en el marco de la recuperación o reafirmación de sus identidades y para ello, construyó formas complejas de organización y de interpelación al proyecto de configuración del Estado-nación. Estas formas de interpelación le dan sentido y constituyen el eje en torno al cual gira toda la trama de relaciones entre el Estado y las nacionalidades indígenas del Ecuador.

Las técnicas iniciadoras en la investigación acción participativa de L. Proaño no han sido estudiadas en profundidad aún por la academia ecuatoriana ni latinoamericana. Hay estudios posteriores publicados en Latinoamérica sobre temas relacionados con la IAP en la educación (Sánchez et. al., 2015); teología (Vélez, 2016); organizaciones barriales (Naranjo, 2017); semiótica (Bacher, 2016); salud de los adultos mayores (López et. al. 2017); praxis investigativa (Paredes \& Castillo, 2017); cooperación internacional y educación intercultural bilingüe (Williamson \& Navarrete, 2014); desarrollo comunitario (Melero \& Aguilar, 2015); educación popular (Morales et. al. 2016); pensamiento complejo (2017); agroecología (Sevilla, 2015); retos con los menores colombianos (Sepúlveda et. al., 2010); pero no indagan en las actividades precedentes pioneras de Proaño con la IAP, entonces denominadas método ver, juzgar y actuar y la teología de los signos de los tiempos. Este artículo se enfoca en las actividades y metodologías más científicos de Proaño, más allá de su religiosidad.

Esta investigación identifica, analiza y rescata los aprendizajes y las experiencias de los procesos de investigación acción participativa realizados por Proaño, en actividades religiosascatólicas y espacios de diálogo-reflexión con indígenas chimboracenses. Sin duda, espacios en los cuales los integrantes de una agrupación o una comunidad excluida: recopilan y analizan información, e intervienen sobre problemas comunes para hallar soluciones que les permitan transformar esa realidad, (Selener, 1997).

Leonidas Proaño, al inicio usó el método de acción católica "ver, juzgar y actuar", basado en la escuela de Bélgica. Tenía tres momentos: el primero, la explicitación de la realidad usando el diagnóstico pastoral y el marco doctrinal; el segundo, la elaboración del marco operacional que debe seguirse; y tercero, la ejecución del plan que permitiría transformar la realidad, (Pellegrino, 2017).

Luego, la teología de los signos de los tiempos desarrollada en América Latina en la etapa postconciliar (Bacher, 2016), que se enfocaba desde tres instancias, en: la primera, el sujeto auscultaba, interpretaba y discernía los signos de los tiempos; la segunda, los procesos de discernimiento se realizaban siempre a partir de lo comunitario; y la tercera, las propuestas se construían desde la participación humana.

Finalmente, utilizó la IAP con fines de transformación de los prejuicios de la sociedad clasista ecuatoriana de la época. El artículo valora las experiencias de diálogo, debate, reflexión y participación realizadas en poblaciones marginadas y analfabetas que, finalmente lograron 
el cambio que les significó ser auto-considerados como seres humanos, con temas como aprender a leer y escribir en su propia lengua (kichwa) y en castellano.

En el texto se utilizan los conceptos del método "ver-juzgar-actuar" y teología de los signos de los tiempos, cercanos por su forma de intervención a lo que hoy se llama investigación acción participativa como dinámica que hace crecer a una comunidad, (Pellegrino, 2017); de comunicación, que es el conjunto de prácticas sociales de acción e interrelación de los sujetos, (Alfaro, 1993); de cambio social, que contribuye a la construcción de sociedades más justas, (Corredor - Aristizábal, 2010); de toma de conciencia, como la búsqueda de causas y consecuencias de un problema de la sociedad, (Proaño, 1974); y de, hombre concreto de Chimborazo, aquel el habitante de un sector geográfico reconocido por sus características (Ibid). Y trata la teoría, frente a su vínculo con la comunicación desde la perspectiva de Barbero (2003); Baudrillard (1984), Canaval (2000); Dubravcic (2002); García (2008); Marcuse (1992); Galeano (1971); Herrera (1992); Igartúa \& Humanes (2010); Kaplún (1983); Lewin (1940); Marcuse (1973); Muñoz (2011); Ossandon (1988); Proaño 1974); Rizo (2012); Serrano (1982); Rojas (2012), entre otros.

\section{Marco Teórico}

\subsection{El Contexto histórico-cultural de Leonidas Proaño}

Leonidas Proaño nació en San Antonio de Ibarra (Ecuador) el 29 de enero de 1910. De padres dedicados a la agricultura y a la confección de sombreros, por su condición de pobreza desde la infancia palpó la exclusión, pobreza y desigualdad como términos ligados a los conglomerados indígenas de América Latina. "Los indígenas no solamente tienen menor acceso a las instituciones sociales y económicas, de desarrollo y bienestar, sino también cuando lo tienen, los resultados para ellos son inferiores al resto de la población", (2001, p. 23). La desigualdad motiva la opresión y la dominación. La dominación se ejerce al restringir el acceso a los recursos materiales y propagar creencias negativas de dominado sobre sí mismo, (Singer, 2011).

El país andino en la época de Don Leonidas estuvo caracterizado por la ruralidad; la población en su mayoría era indígena. "El 78\% vivía en el campo y la concentración urbana solo se daba en Guayaquil y Quito", (Naciones Unidas, 1954, p. 14). Hacinados en las haciendas trabajaban como husasipungueros (trabajadores de un pequeño trozo de tierra obligados a repartir sus cosechas a cambio de la posesión del terreno). En las visitas pastorales al campo constató las condiciones en las que vivían estas personas y marcaron proximidad con lo que vivió en su niñez. "Los indios debían al encomendero servicios personales y tributos económicos, no era mucho el tiempo que quedaba para introducirlos en el cristiano sendero de la salvación", Galeano (1971, p. 62).

Proaño, trabajó sobre la base del método de acción católica "ver, juzgar y actuar" empleado por la Juventud Obrera Católica (JOC), fundada en Bruselas en 1912, por el sacerdote Joseph Cardijn; proponía un contexto de cambio profundo en el que el movimiento social católico necesitaba transformarse, (Sanz, 2001). Un año después de ser ordenado sacerdote, en 1937, conformó una organización similar de trabajadores católicos y adecuó la propuesta religiosa a la realidad de Ibarra (Proaño, 2011).

La iglesia católica no estaba alejada de la explotación a través de la tenencia de la tierra. Proaño, una vez nombrado obispo, en 1954, repartió una hacienda a cooperativas comunitarias 
agrícolas, inicio de la reforma agraria en el país. Camilo Ponce fue electo presidente de Ecuador en 1956, miró lo que se hacía en Chimborazo y "promovió la modernización del agro expidiendo en mayo de 1959 la Ley de Reforma Agraria entregando gratuitamente una parte de la tierra a los campesinos" (p. 22), con lo que la parcelación se extendió en todo el Ecuador.

Evolución del ver juzgar y actuar, a la teología de los signos de los tiempos, y a la IAP Como obispo se vinculó con las necesidades indígenas. Con el método de acción católica y con la teología de los signos de los tiempos buscó el cambio de las personas con principios éticos recogidos en las escrituras bíblicas, al inicio; y después con teorías más sociológicas, antropológicas y educativas. Su práctica es cercana a la IAP, propuesta de Kurt Lewin (1946), que pretende atender las necesidades de los miembros de la comunidad; en Latinoamérica fue desarrollada formalmente por el colombiano Fals Borda en 1977, (Bacher, 2016).

El método "ver, juzgar y actuar", para Castillo, Viga \& Dickinson (2008) exige la observación, el análisis y la reflexión de los resultados para volver a iniciar el ciclo (feedback). Leonidas Proaño en las comunidades indígenas de Chimborazo: escuchaba (ver) la realidad de los indígenas, hacía un análisis de conjunto (juzgar desde el evangelio) e intervenía para cambiar esa realidad (actuar).

La teología de los signos de los tiempos buscaba la interpretación de estos y cómo incidían en la gente, (Silva, 2009). Fue propuesta por Papa Juan XXIII en el Concilio Vaticano II (1962-1965); en América Latina, el Encuentro de Medellín en 1968 fue el punto de partida; se identificó como sujeto para el juzgamiento al Pueblo de Dios en el que estaban incluidos pastores y laicos comprometidos con el cambio social. En esta teología la gente es quien toma la decisión sobre sí misma y su transformación, pero en comunidad.

Raúl Rojas (2012) dice que la IAP provoca al proceso de cambio social un giro metodológico. Podría describirse cómo,

1. La investigación: estudio de la realidad;

2. La acción: desde la reflexión-comprensión de esa realidad para propender al cambio social a través el ejercicio de una praxis plena; $y$,

3. La participación: desde lo colectivo y lo comunitario entendido como la suma de voluntades para transformarse en conjunto.

La investigación acción participativa toma como punto de partida la necesidad sentida por la comunidad; $y$, las preguntas problematizadoras que dan lugar a un proceso que permite percibirla como una necesidad real. (Bacher, 2016, p. 35). La intervención de la gente es esencial para alcanzar los objetivos transformadores.

Fals Borda que la introdujo en América Latina la reflexionó cómo "el principio de la autonomía [...] implica el reconocimiento de los talentos y fuerzas en el conjunto del pueblo que por regla general han sido bien ignorados por la clase dominante", (Borda en Bacher, 2016, p. 34).

Olga Vélez (2006) añade que, dentro de las ciencias sociales, la IAP tiene una larga tradición en América Latina, porque promueve la transformación de la sociedad.

Park (2011, p. 137), señala que es:

Una manera intencional de otorgar poder a la gente para que pueda asumir acciones eficaces hacia el mejoramiento de sus condiciones de vida. Lo novedoso no es que la gente se cuestione sobre sus condiciones y busque mejores medios de actuar para su bienestar 
y el de su comunidad, sino el hecho de llamar a este proceso investigación y de conducirlo como una actividad intelectual.

Insiste Vélez (p. 191) que existe una contraposición de esta metodología con la investigación tradicional. La finalidad de la investigación acción participativa, para Bacher está en la praxis no necesariamente vinculada con lo académico, en la conexión directa con la realidad y explicarla para transformarla. Es una metodología de estudio-acción que pretende resultados que sirvan para la transformación colectiva.

Urdapilleta y Limón (2018) dicen que no puede abordarse la IAP sin considerar a Paulo Freire y a Orlando Fals Borda. El primero con la Pedagogía del Oprimido publicada a finales de 1960 y el segundo, Ciencia propia y colonialismo intelectual en 1970. Analizan el sistema educativo popular como generador de cambios de actitudes y de toma de conciencia.

Freire y Fals Borda miraron la propuesta de Gramsci (1970), explorando desde la razón las formas de emancipación como un proceso histórico y material.

Dado que la tendencia sigue siendo asumir que quienes realizan la investigación se deben mantener el margen del proceso de transformación, el riesgo es que se omita que son por igual sujetos en transformación. esto incluye las relaciones afectivas que puedan generarse dentro de tales procesos, en los que lo vivencial y las emociones vertebran esta opción esta opción sociológica y académica en general, (Urdapilleta \& Limón, 2018, p. 115).

La propuesta plantea que se debe estar junto a los seres humanos marginados, excluidos y desposeídos para convertir a la tierra en el verdadero paraíso (Ibid). Wals (2007) concibe a la experiencia participativa como un medio sociocognitivo que privilegia la consecución de aprendizajes conjuntos, de maneras de aproximarse unos con otros, de mecanismos de convivencia, de cercanías y de encuentros.

Kemmis \& Mc Taggart (2005) sitúan a la IAP como una espiral que exige, elegir una comunidad y en ella un problema; trazar un plan de acción; y finalmente, actuar para solucionarlo.

De esta forma una de las aportaciones y enfoques teóricos originales de esta investigación es el destacar el paralelismo entre la investigación acción participativa con el método "ver, juzgar y actuar" y la teología de los signos de los tiempos; para los autores de este artículo, los tres comparten el fundamento teórico-práctico y alcanzan similares resultados puesto que se enfocan en el diagnóstico, la discusión-debate de los problemas comunes, y la transformación desde lo participativo.

Es necesario hacer hincapié que, para efectos del presente trabajo, la aproximación científicametodológica de Proaño y sus acciones sociales, transcienden la temporalidad en la que surgieron la nomenclatura método "ver, juzgar y actuar", la teología de los signos de los tiempos, y en su práctica pueden considerarse como investigación acción participativa dado los múltiples denominadores comunes naturales y experimentales descritos en la figura 1. 
Figura 1. Coincidencias del método ver, juzgar y actuar; teología de los signos de los tiempos; y la investigación acción participativa.

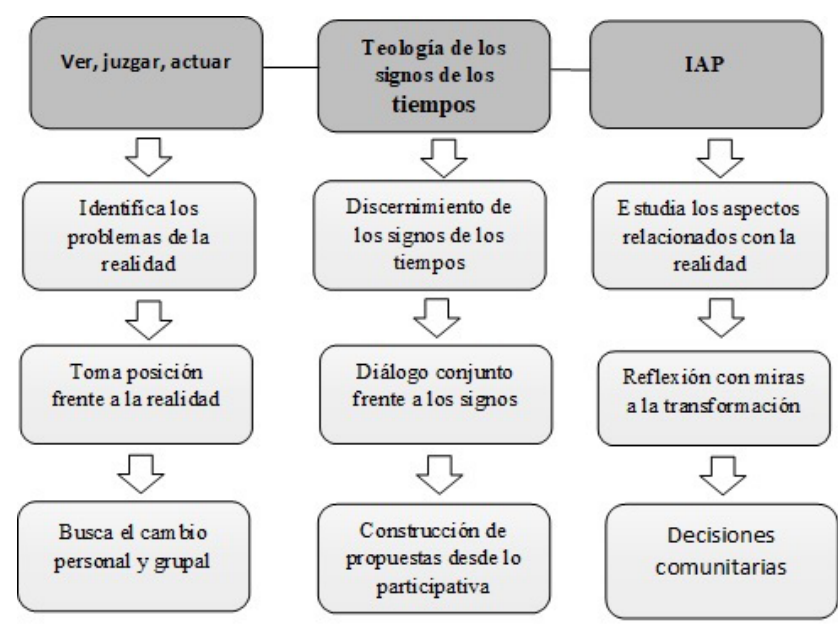

Fuente: Elaboración propia a partir de las propuestas: Bacher. Castillo, Viga \& Dickinson y Borda.

\subsection{La IAP y la comunicación}

La aproximación de Teoría de la Comunicación, expresada por Manuel Martín Serrano (1982, p.18) se integra a los procesos desarrollados por Leonidas Proaño basados en la investigación acción participativa mediante el uso de la comunicación humana, biológica y tecnológica (prensa y radio) la comunicación permite que "algunos seres vivos pueden relacionarse con otros seres vivos intercambiando información". La evidencia está en la proximidad con los indígenas de Chimborazo; con el diálogo conoció sus carencias, los escuchó y encarnó una problemática. La comunicación por ser una forma de interacción, supone la participación de al menos dos Actores. En la situación comunicativa, los Actores ocupan posiciones distintas y en el transcurso del proceso comunicativo desempeñan funciones diferentes (Serrano, 19982, p. 19).

En las comunidades indígenas se realizaba asambleas; se plateaban preguntas sobre problemas del entorno y se escuchaban las respuestas, luego serían sistematizadas (clasificadas y jerarquizadas). El momento culminante eran las conclusiones porque pasaban a la ejecución de las propuestas (participativas) para el cambio social.

La Teoría de la Acción Comunicativa (Habermas, 1987) profundiza los estudios sobre la realidad social delineando dos formas de interacción: el trabajo y la comunicación, porque los actos comunicativos cumplen una función de integración y de mantenimiento del sistema social. Serrano distingue igual actos ejecutivos de expresivos, y Proaño usó la comunicación para apoyar la evolución socio cultural de los "indios" promoviendo actos comunicativos para expresar sus necesidades y derechos que pudieran sustituir actos ejecutivos que no fueran tan productivos. Uno de los actos ejecutivos era el reconocimiento de los indígenas que había una realidad de marginación y opresión que debía transformarse, y el deseo de hacerlo. Y, cuando hubo empatía entre comuneros y prelado, las muestras de alegría en los encuentros se traducían en cooperación, como un acto expresivo. 
La propuesta de Rizo (2012, p. 21) demuestra que lo importante de la comunicación ejercida por Proaño era la búsqueda de esa capacidad para relacionarse con los demás, pero, tomando el rol de actor. "la función básica de la comunicación humana es desarrollar relaciones, más que intercambiar información". Definir los problemas (desigualdad, exclusión, marginación, opresión, dominación) y saber cómo resolverlos, fue un intercambio de información que sirvió para desarrollar relaciones entre las comunidades indígenas y las mestizas, para motivar la empatía y el cambio social del respeto enmarcado en los derechos humanos. Se dejó de lado la unidireccionalidad comunicativa y la reemplazó por la doble vía porque le garantizaba que un "abordaje de la comunicación debe tomar en cuenta esta diversidad de perspectivas y acercamientos", (Rizo, 2018, p. 1).

Las formas utilizadas por Proaño para relacionarse con los indios y de obtener información usando el diálogo, pueden tener un enfoque subjetivo, aspecto enfocado por Herbert Marcuse en 1929. "El subjetivismo, cuanto postura ontológica, tiene que refugiarse en la cada vez más evanescente concepción abstracta del ser de lo real", (Muñoz, 2011, p. 3). El conjunto de relaciones humanas (actores del proceso de comunicación) provocadas con los actos comunicativos ejercidos por Don Leonidas proyectaron una imagen semejante a los tres niveles expresados por Baudrillard (1984): la imagen representa la realidad; la imagen enmascara la realidad; en la realidad no existe solo símbolos.

Con estos actos comunicativos nació en las comunidades indígenas de Chimborazo la comunicación popular que para Ossandon (1988, p. 50), es:

Ante todo, la comunicación popular ya es "un dato" de la realidad. Existe un amplio conglomerado de prácticas de elaboración y/o consumo de mensajes que provienen del pueblo y se dirigen prioritariamente a él. En ocasiones, se dirigen a la sociedad en su conjunto Adquieren formas e intensidades diferentes. según el país o sector en el cual se originan.

Dubravcic (2002) dice que la comunicación popular se distingue como una práctica de intercambio cultural y simbólico entre actores sociales con diversidad. Para Kaplún (1983, p. 40) esta comunicación es alternativa porque se encontró con "Carentes de condiciones para enfrentar a las grandes redes masivas, sin peso para incidir en las políticas nacionales de comunicación".

El aparecimiento en la década del sesenta de la radio popular en el Ecuador, creada por Leonidas Proaño con fines alfabetizadores de la gente del campo y de los sectores urbanomarginales impulsó nuevas escenografías; y, presentó otra forma de hacer comunicación.

García, D. (2008, p. 127):

En el año 1962, Monseñor Leonidas Proaño decide fundar las Escuelas Radiofónicas Populares de Ecuador (ERPE). Él, obispo de los Indígenas y los Pobres, consideraba que a la pobreza había que combatirla con educación y para llegar a los indígenas que se encontraban entre los páramos del Chimborazo, nada mejor que una radio.

\section{Metodología y muestra}

La presente investigación es mixta cuantitativa - cualitativa a partir de la revisión documental combinada con el análisis de contenido. De tipo cualitativa que es una categoría de diseño de investigación que, da prioridad a la comprensión y al sentido, en un procedimiento que 
tiene en cuenta las intenciones, las motivaciones, las expectativas, las razones, y las creencias de los individuos, (Monje, 2011); y, cuantitativa porque usa instrumentos de medida como la estadística para precisar las observaciones, análisis e interpretación de resultados, (Gómez, Deslauriers y Piedrahita, 1990).

La muestra observada corresponde a 153 actividades registradas en los libros y actas de reuniones desarrolladas con nueve organizaciones indígenas y sociales, y 347 contenidos recogidos en los 94 números de la revista Mensaje que circuló entre 1954 a 1961. La información corresponde a jornadas de capacitación, discusión y difusión, utilizando la investigación acción participativa.

Se utilizaron como técnicas:

a) Revisión documental que busca representar el contenido de manera distinta a su forma original; es una labor intelectual porque el investigador se centra en la interpretación y análisis que le permite construir un nuevo producto para la difusión. "Debe considerarse exclusivamente como descripción del contenido y no como descripción formal", (Clauso, 1993, p. 11). b) Análisis de contenido como conjunto de instrumentos metodológicos, aplicados a lo que se denomina como discursos (contenidos y continentes) extremadamente diversificados, (Bardin,1986, p. 7). López (2002) lo define como método para estudiar y analizar las comunicaciones de una forma sistemática, objetiva y cuantitativa.

Tabla 1. Tipo. nombre y año de las publicaciones sobre los que se realizó la revisión documental y el análisis de contenido.

\begin{tabular}{c|l|c}
\hline \multicolumn{1}{c|}{ TIPO/MEDIO } & \multicolumn{1}{|c}{ DOCUMENTO } & AÑO DE PUBLICACIÓN \\
\hline Impreso & Revista Mensaje & 1954 a1961 \\
\hline Radio & Programa Hoy y mañana & $1970-1981$ \\
\hline Libro & $\begin{array}{l}\text { Concientización, evangelización, } \\
\text { política }\end{array}$ & 1974 \\
\hline Libro & Evangelio Subversivo & 1976 \\
\hline Actas & $\begin{array}{l}\text { Reuniones de trabajo de las } \\
\text { comunidades eclesiales de base; } \\
\text { Frente de Solidaridad; Comité de } \\
\text { Derechos Humanos }\end{array}$ \\
\hline Libro & Abriendo surcos indígenas 1 & 2011 \\
\hline Libro & Abriendo surcos indígenas 2 & 2011 \\
\hline
\end{tabular}

Fuente: Elaboración propia - repositorio: Fondo Documental Diocesano

El proceso se desarrolló durante cinco etapas (Ver Figura 2): La primera, en el Fondo Documental Diocesano de Riobamba, en él reposan las 94 ediciones de la revista Mensaje (1954-1951) y los libros y actas que recogen las actividades desarrolladas con agrupaciones indígenas, sindicales, mujeres, jóvenes y maestros; segunda, recuperación y recogida de información 
con el instrumento (matriz de análisis, diseñada por los investigadores), descrita como función preparatoria por Galdón (2002, p. 70) que, consiste en entregar a cada investigador la información de primera mano; tercera, la jerarquización de la temática llamada función crítico-verificadora, (Ibid) que significa comprobar la exactitud de los hechos con otras fuentes y clasificarlos según el nivel de importancia y de significación, que para Bravo (2011) equivale a establecer el nivel de confiabilidad de la información; cuarta, selección y valoración, para el profesor Galdón es la función completiva ya que le permite al investigador contextualizar los hallazgos, y clasificarlos en orden de importancia; quinta, discusión y presentación de resultados, mediante el contraste con la fundamentación teórica.

Figura 2. Etapas del proceso de análisis de contenido a la revista Mensaje y los documentos de actividades desarrolladas por Leonidas Proaño.

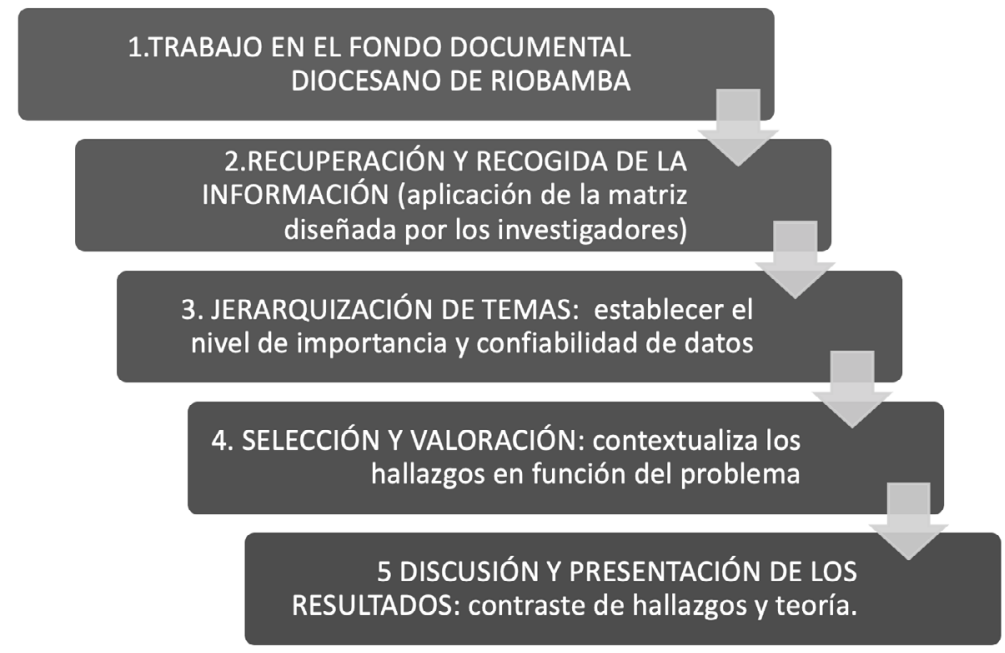

Fuente: Elaboración Propia

La revista Mensaje fue el órgano oficial de difusión de la Curia de Riobamba. Utilizada para la difusión de las actividades pastorales, sociales, educativas, sindicales y las visitas a los sectores urbanos y rurales. Y también están los originales de las actas de reuniones y libros que recogen las acciones en las que se obtuvo información a partir del uso de la IAP.

Para la recuperación y recogida de la información, la ficha elaborada para utilizar la matriz tuvo un diseño que permitió evidenciar en una columna el nivel semántico ¿qué dice?; en la siguiente identificar las categorías (el listado de palabras que demuestran el paso desde el evangelio católico hasta lo ético y derechos humanos; y en una tercera, el nivel pragmático ¿cómo lo dice? Estos tres elementos permitieron identificar de qué manera en la Diócesis se trabajó para que: a) se conociera la realidad de los indígenas de Chimborazo (Visita Pastoral); b) se elaborara el proyecto de acción con miras a la transformación integral del "hombre concreto" de Chimborazo, "el hombre situado en una geografía y rodeado de condiciones concretas" (Proaño, 1974, p. 103).

En el trabajo se observó cada una de las 94 ediciones de la revista Mensaje, se estudió cada libro 
publicado y se analizaron 49 actas de encuentros con indígenas y organizaciones; 53 guiones del programa radiofónico Hoy y mañana. Los datos se jerarquizaron según las actividades de investigación acción participación; interrogantes aplicadas en la acción; categorías discursivas; y actos comunicativos; en la selección y valoración se escogieron los resultados en tablas. En la discusión y presentación, los contenidos fueron ordenados e interpretados.

Organizar la documentación según la publicación, medio de difusión, y analizar el tipo de comunicación sirvió para identificar las etapas de la IAP y el vínculo con los actos comunicativos (escucha durante las visitas, diálogo como herramienta de los encuentros y difusión usando la radio y la prensa).

\section{Resultados}

Los datos que contienen las tablas que aparecen este epígrafe (Actividades de investigación acción participativa realizadas por Proaño, 1954-1988; Interrogantes utilizadas como parte de la IAP en los encuentros, jornadas de reflexión, seminarios, entre otros; Categorías discursivas empleadas por Proaño; Clasificación de los actos comunicativos en las actividades de investigación acción participativa;) se recopilaron mediante la utilización de las matrices diseñadas para la revisión documental y el análisis de contenido que tuvieron cuatro entradas. La primera, condensa la información general: encabezado, fecha del trabajo, hora, nombre de la publicación, participantes y observaciones. La segunda, contiene el nivel semántico es decir el ¿qué dice? Identificó los verbos vinculados con la acción (durante reuniones de trabajo, encuentros y plenarias). La tercera, recoge las categorías. La cuarta, es una explicación del ¿cómo lo dice? puesto cada una de las etapas de la investigación acción participación tuvieron características propias y palabras clave acorde con ellas. Los instrumentos sirvieron para identificar la aplicación de la IAP que distinguieron a Proaño como un científico social.

Tabla 2. Actividades numeradas de la investigación acción participativa realizadas por Proaño (1954-1988)

\begin{tabular}{|l|l|}
\hline INVESTIGACIÓN & $\begin{array}{l}\text { 1. La Visita Pastoral a la Diócesis, realizada en 1955 le permitió tener un } \\
\text { primer contacto con los problemas de los indígenas que habitaban en } \\
\text { las comunidades. }\end{array}$ \\
& $\begin{array}{l}\text { 2. Después del primer encuentro, se organizó el diagnóstico como } \\
\text { instrumento para la construcción del plan de acción, que estaría listo } \\
\text { para } 1956 .\end{array}$ \\
& $\begin{array}{l}\text { 3. Todos los sábados de } 1954 \text { a } 1985 \text { tuvo audiencias en la Diócesis. } \\
\text { Recibió cientos de personas de todas condiciones que le pusieron al } \\
\text { tanto da situación de injusticia, marginación y opresión. } \\
\text { 4. Cada domingo de } 1954 \text { a } 1985 \text { visitó el campo para comprobar lo que } \\
\text { en el despacho le contaban los indígenas y confirmar la importancia } \\
\text { de impulsar el proyecto que modifique socialmente a estas parroquias, } \\
\text { caseríos, anejos }\end{array}$ \\
\hline
\end{tabular}




\begin{tabular}{|c|c|}
\hline ACCIÓN & 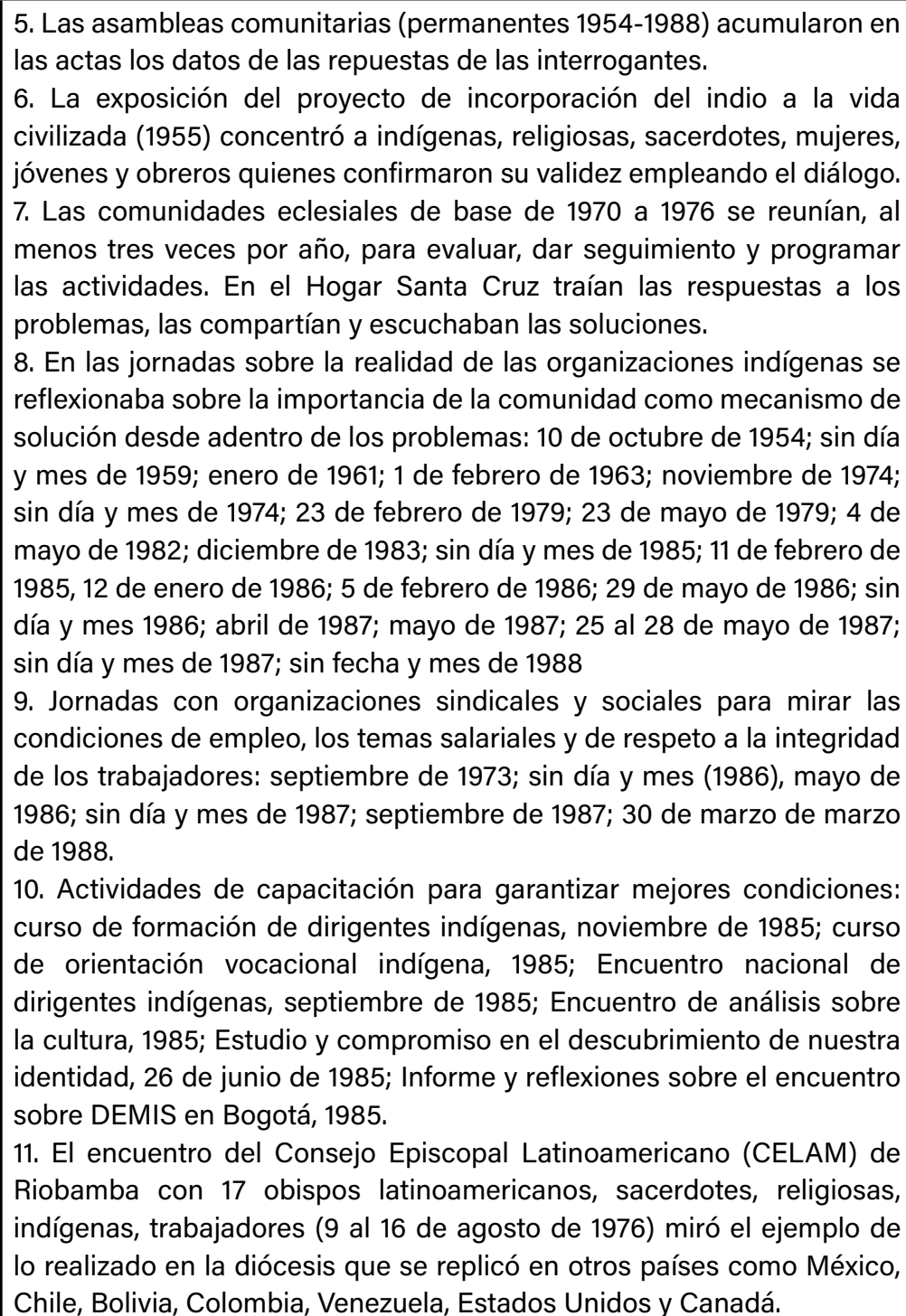 \\
\hline
\end{tabular}




\begin{tabular}{|c|c|}
\hline PARTICIPACIÓN & $\begin{array}{l}\text { 2. Construcción del plan de acción para incorporar al indio a la vida } \\
\text { civilizada (1955). } \\
\text { 13. } 19 \text { de enero de 1958. la Misión Andina en Ecuador comienza a trabajar } \\
\text { en Riobamba, en un área de } 500 \text { kilómetros cuadrados. } \\
\text { 14. En } 1960 \text { crea el Centro de Estudios y Acción Social desde donde se } \\
\text { atienden programas de cooperativismo y desarrollo. } \\
\text { 15. En } 1962 \text { funda Escuelas Radiofónicas Populares del Ecuador para } \\
\text { impulsar el proyecto de alfabetización del indigenado. } \\
\text { 16. En } 1965 \text { se crea al periódico Jatari Campesino con complemento de la } \\
\text { radio para impulsar programas de alfabetización. } \\
\text { 17. 1976, inicio del sistema de teleducación, nueva modalidad de } \\
\text { alfabetización utilizando las ondas de la radio. } \\
\text { 18. En } 1986 \text { se crea la Vicaría de la Pastoral Indígena y la Coordinación } \\
\text { Diocesana de Pastoral Indígena. }\end{array}$ \\
\hline
\end{tabular}

Fuente: Elaboración propia

La tabla clasifica las actividades de investigación acción participación desarrolladas durante 34 años en las comunidades indígenas de Chimborazo. Con el uso de la IAP los pueblos deprimidos empezaron procesos de construcción en conjunto de otra realidad con lo que se denomina cambio o transformación social, que tiene como objetivo buscar una sociedad más libre, justa y solidaria, (Alcántara \& Sampaio, 2013).

Tabla 3. Interrogantes utilizadas en la etapa de acción en los encuentros, jornadas de reflexión, seminarios, entre otros

\begin{tabular}{l|l}
\hline PASTORAL & $\begin{array}{l}\text { ¿Cómo despertar la sensibilidad del indígena frente a Dios? ¿Cómo } \\
\text { en su corazón debe reinar el amor a la vida y al Creador? ¿La } \\
\text { evangelización les permitirá reconocerse como Hijos de Dios? ¿Qué } \\
\text { objetivos debería perseguir una iglesia viva? ¿Es posible la creación } \\
\text { de una Pastoral indígena? ¿Por qué los valores fundamentales son } \\
\text { considerados como la Semilla del Verbo? }\end{array}$ \\
\hline SOCIAL & $\begin{array}{l}\text { ¿Por qué son indiferentes ante el dolor de sus hermanos indígenas? } \\
\text { ¿Cuáles son los problemas cotidianos en las comunidades? ¿Qué hacer } \\
\text { para que se despierten sus aspiraciones de cambio? ¿Cuestionamientos } \\
\text { frente al trabajo que se realiza en las comunidades? ¿Cuáles son sus } \\
\text { valores fundamentales? ¿¿Por qué los pobres están marginados de la } \\
\text { vida pública? ¿Por qué los pobres no tienen derecho a acceder a los } \\
\text { medios de comunicación social? ¿Cuáles son las grandes aspiraciones } \\
\text { del hombre de Chimborazo? ¿Qué mecanismo seguir para resolver los } \\
\text { problemas vitales de las comunidades? ¿Cómo sensibilizar a los ricos } \\
\text { de la importancia de mirar a los pobres como iguales? ¿Cómo lograr } \\
\text { que los indígenas sepan leer y escribir? }\end{array}$
\end{tabular}




\section{POLITICICO/ GREMIALES}

¿Datos sobre la población indígena del Ecuador? ¿Posesión de la tierra? ¿Quiénes pisotean a los campesinos marginándoles de elegir y ser elegidos? ¿Por qué los pobres no tienen vida política? ¿Qué pasos deben seguirse para la formación de líderes que lleguen a cargos públicos? ¿Las candidaturas a cargos de elección popular son fruto del consenso? ¿Qué derechos de los obreros están siendo vulnerados? ¿Los pagos que reciben los trabajadores están en proporción de las actividades? ¿Se respeta el derecho a la huelga? ¿Por qué no se contratan mujeres? ¿Las conquistas alcanzadas con la firma de los contratos colectivos son respetadas?

Fuente Elaboración propia

Esta tabla contiene las principales interrogantes que se emplearon para la acción, en cada uno de los encuentros realizados; la sistematización de sus respuestas contiene datos de importancia para la transformación social.

Tabla 4. Valores desde el evangelio católico y lo ético-derechos humanos

\begin{tabular}{c|l}
\hline \multicolumn{2}{c}{ Valores Evangelio Católico - Ético - Derechos Humanos } \\
\hline \multicolumn{1}{c|}{ INVESTIGACIóN } & \multicolumn{1}{c}{ ACción } \\
\hline Catecismo, creación, religiosas, comunión, \\
teología, palabra, salvación, encarnación, \\
resurrección, homilías, sacerdocio, vocación, \\
$\begin{array}{l}\text { actitud, fe, pecado, pecador, limosna, } \\
\text { esperanza, renovación, espiritual, justicia } \\
\text { social, recompensa, renovación, verdad, } \\
\text { transformación, movimientos, instituciones, } \\
\text { respeto, derechos, humanismo. }\end{array}$ \\
\hline
\end{tabular}

Fuente Elaboración propia

Los valores evangelio católico y ético-derechos humanos, que constan en la presente tabla, sirven para una comprensión de la utilización en cada una de las etapas de la investigación acción participación. La identificación de los valores bíblicos y los principios recogidos en los Derechos Humanos declarados el 10 de diciembre de 1948, se realizó mediante una tabulación e identificación de aquellas categorías repetidas con mayor frecuencia en: asambleas comunitarias y apariciones públicas del obispo, así como en los contenidos difundidos por prensa y radio. 
Tabla 5. Clasificación de los actos comunicativos en las actividades de investigación acción participativa.

\begin{tabular}{|c|c|c|}
\hline \multirow[t]{3}{*}{ ACTOS COMUNICATIVOS } & $\begin{array}{l}\text { ESCUCHA/ } \\
\text { INVESTIGACIÓN }\end{array}$ & $\begin{array}{l}\text { a) Visitas pastorales } \\
\text { b) Visitas a comunidades } \\
\text { c) Audiencias en su despacho } \\
\text { d) Visitas a los barrios }\end{array}$ \\
\hline & DIÁLOGO/ACCIÓN & $\begin{array}{l}\text { e) Jornadas de reflexión; f). encuentros } \\
\text { de pastoral; g) asambleas comunitarias; } \\
\text { h) mingas; homilías; i) reuniones con } \\
\text { mujeres, obreros, jóvenes, indígenas; } \\
\text { k) mesas redondas; l) conferencias; m). } \\
\text { seminarios. }\end{array}$ \\
\hline & $\begin{array}{c}\text { DIFUSIÓN/ } \\
\text { PARTICIPACIÓN }\end{array}$ & $\begin{array}{l}\text { n) En la revista Mensaje } 45 \text { crónicas, } \\
216 \text { noticias, } 63 \text { comunicaciones } \\
\text { diocesanas (cartas episcopales, } \\
\text { circulares, exhortos, edictos, boletines), } \\
23 \text { espacios de opinión. } \\
\text { o) En el programa radiofónico Hoy y } \\
\text { mañana difundido por ERPE. L. Proaño, } \\
\text { leía cartas con respuestas de indígenas } \\
\text { las preguntas formuladas y difundía } \\
\text { temas de relevancia (1970-1981). } \\
\text { p) Misión Radial (1973), proceso de } \\
\text { evangelización } \\
\text { q) Denuncia del apresamiento de los } \\
\text { integrantes del CELAM } \\
\text { r) Escribió editoriales en el periódico } \\
\text { Jatari Campesino } \\
\text { s) Concedió entrevistas a medios } \\
\text { locales y nacionales. }\end{array}$ \\
\hline
\end{tabular}

Fuente Elaboración propia

La Tabla 5 vincula la IAP con los actos comunicativos (humanos, biológicos y tecnológicos) de Leonidas Proaño; en ella está la justificación de la denominación de pionero en lo científico, pero también de lo comunicacional; para cada una de las etapas de la metodología empleó una técnica distinta: investigación (escucha); acción (diálogo); y participación (difusión).

\section{Discusión}

Leonidas Proaño usó la IAP por para implementar el cambio social en las comunidades indígenas de Chimborazo y en organizaciones sociales. Evidencia que demuestra lo realizado después del análisis documental que se recoge en las tablas de recopilación de datos y que a continuación se comentan y describen en profundidad: 


\subsection{Investigación acción participación}

La tabla 2 separa las actividades y las clasifica a partir de los tres componentes (investigaciónacción-participación). En la investigación fase vinculada con la escucha, componente del literal a) de la tabla 5, se identifican hechos como la Visita Pastoral que empezó el 14 de julio de1955; Proaño escuchó y recopiló datos: injusticia y marginación; analfabetismo; limitada tenencia de la tierra. La información sirvió para el: "proyecto para incorporar al indio a la vida civilizada" presentado el 25 de noviembre de 1956; actividad vinculada con el numeral 6 de la fase acción y con el numeral 12 de la fase participación, y también con el diálogo como acto comunicativo detallado en la tabla 5. Se observó que los fines de semana visitó a campesinos y atendió audiencias en su despacho; actividades para acumular información y difundirla en medios masivos, conferencias, seminarios y en homilías; sirvió para hacer procesos iterativos de investigación y acción motivando a la participación.

La acción, durante seis años motivó la inter-relación y respuesta de interrogantes en las asambleas comunitarias como las eclesiales de base, actividad que se vincula con el numeral 7 de la tabla 2, que es parte de la etapa de diálogo que consta en el literal g) de la tabla 5.

El encuentro del CELAM, en 1976, descrito en el numeral 11 de la tabla 2, se complementa con el literal q) de la tabla 5 porque en él reflexionaron a partir de interrogantes relacionadas con la transformación de los indígenas y corresponde a la fase diálogo/acción. Lo aprendido en la diócesis de Riobamba (organización, intervención y participación) fueron referencia para 17 obispos de América. Latina que a mitad del encuentro fueron apresados y desterrado del país, por planificar acciones que según la dictadura militar de la época eran subversivas.

La participación, se pudo observar que fue multisectorial y no solo de entidades vinculadas con la iglesia, los datos que a continuación se expresan afirman lo expuesto.

El "proyecto para incorporar al indio a la vida civilizada" fue debatido en la fase de acción, numeral 6 de la tabla 2. Se ejecutó en 1956. Fue construido participativamente como lo detalla el primer numeral 12 de la tabla 2 y se vincula con la fase difusión/participación de la tabla 5 , literal n) ya que aparece en uno de los contenidos de la revista Mensaje. Sus ejes: la creación de un Centro de formación indígena en Tepeyac; funcionamiento del Seminario Menor La Dolorosa; creación de la pastoral indígena; inclusión de las religiosa lauritas en el trabajo con las mujeres; creación del normal (instituto) católico para formar maestras; motivar procesos de alfabetización; formar sacerdotes indígenas.

La creación de las Escuelas Radiofónicas Populares del Ecuador, en 1962, consta en el numeral 15 de la tabla 2; combatiría la pobreza desde la educación (García, 2008). Con ERPE se formalizó la educación y la radio popular; 18.000 indígenas aprendieron a leer y a escribir. Como se explica en el literal o) de la tabla 5, fase difusión/participación, Proaño tuvo su programa de radio que estuvo 11 años al aire; no se ocupó solo de la evangelización sino también de la educación y la lectura de las cartas de los oyentes, estrenó la interactividad con los indígenas como protagonistas.

El involucramiento de la gente en acciones de participación demandaba según Proaño (1974), dejar de ser pasivos, no quedarse en el aplauso luego de los discursos, sino darse cuenta de su riqueza y de la unidad para cambiar su situación. La transformación ha sido pensada y 
desarrollada desde lugares propios (Huergo, 2002), por eso las constantes visitas y actividades a las comunidades para administrar relaciones con y entre semejantes.

\subsection{Preguntas utilizadas para acompañar la fase acción}

La Tabla 3 agrupa las preguntas utilizadas a través de la aplicación de la IAP. Se plantearon en las reuniones de trabajo; los encuentros de las comunidades eclesiales de base, organizaciones sindicales y pastoral indígena. Los interrogantes seleccionados son trascendentes porque están en concordancia con todos los numerales de la fase acción que se encuentra en la tabla 2 y se enfocan hacia el cambio social. Taita Proaño fue persistente en la aplicación de la investigación acción participativa que, "en su propósito de transformar la problemática social identificada, también reivindica la intersubjetividad y los contextos culturales e históricos de los procesos de investigación", (Guardiola, 2017. P. 94).

Las preguntas y respuestas fueron el instrumento participativo de diagnóstico para intervenir en la realidad de la gente de este sector deprimido de Ecuador; con los datos, en conjunto, se delineó un plan de acción que solucione el analfabetismo, acceso a los servicios básicos, la inequidad social; y para definir las características del "hombre concreto" de Chimborazo.

\subsection{Valores desde el evangelio católico y lo ético-derechos humanos}

Como se expresa en la Tabla 4 la investigación/escucha, la acción/diálogo y la participación/ difusión de los procesos de cambio social requerían valores comunes que al inicio eran los discursos evangélicos católicos y después objetivarse en un elemento más contemporáneos con el surgimiento de debates éticos y sobre los derechos humanos para llegar a todos los sectores de la sociedad, católicos y no católicos; dos tipos de categorías (evangelio/ católico y ético/derechos humanos) las que. Muestran una evolución para generar empatía entre indígenas y mestizos a través de una construcción semántica que contenga elementos discursivos que unan religión con protección de derechos.

El resultado de la tabla 4 invita a re-pensar de qué manera se llegaba a la gente pobre y descartar que únicamente haya sido con la religión católica. Hablar de reivindicar los derechos humanos en una época en que la oposición empezaba por el ala conservadora de la iglesia, le llevaron a Proaño a ser calificado de obispo rojo o comunista, e incluso a recibir un delegado de la Santa Sede; el sacerdote Julio Casanova se entrevistó con unas 2.000 personas y luego de un análisis concluyó que las acusaciones no tenían sustento, así refleja el guion del programa Hoy y mañana del 7 de diciembre de 1973. Este contenido está en concordancia con el literal q) de la tabla 5, fase difusión/participación.

\subsection{Actos comunicativos: humanos, biológicos y tecnológicos, para apoyo al desarrollo de la IAP}

La tabla 5 describe los actos comunicativos que se encuentran inter-relacionados con todas fases de la investigación (escucha) acción (diálogo) participativa (difusión).

Escucha: la edición de la revista Mensaje del 16 de julio de 1955 publica la visita realizada a la parroquia Echeandía literal a) de la tabla 5, fase escucha/investigación; literal n) de la tabla 5 fase difusión/participación, y guarda concordancia con la tabla 2, numeral 1 fase investigación. Explica la escucha y difusión de problemas: años sin párroco, sin templo y sin obras para vivir como seres humanos. 
Escuchar a los indígenas fue algo cotidiano para Don Leonidas: en su despacho recibía a autoridades a pedir favores como la designación de párrocos; niñas que querían conocerlo; indígenas a pedir cerrar las chicherías (cantinas) porque envenenaban a hombres y mujeres.

Diálogo: los encuentros que se desarrollaban tenían una estructura definida, literal f) tabla 5 fase diálogo/acción; en uno de ellos se plantearon tres preguntas: ¿integración del indígena? ¿,cómo hallar la liberación de la opresión y toda forma de esclavitud? ¿cómo lograr una participación conjunta para resolver los problemas desde adentro?; luego, en grupos de trabajo de hasta ocho integrantes las respondieron; los criterios más importantes eran expuestos por el secretario relator en la plenaria. Dinámica que se cumplió en la jornada de agentes de pastoral y laicos, del 3 al 10 de enero de 1973, en Columbe. Dos respuestas llamaron la atención "ANTES: eran considerados animales; HOY: se han situado como seres humanos", (Proaño, 2011).

Por lo tanto, al diálogo debe considerarse como una de las fortalezas del trabajo con la IAP, su validez es la praxis participativa. En las reuniones de las comunidades eclesiales de base que entre 1970 y 1976 conformaron 122 grupos, reunió a 345 integrantes de los que al final quedaron solo 39, literal g) de la tabla 5 fase difusión participación.

Difusión: su aparición en medios como periodista o como entrevistado, el uso de la radio para alfabetización, evangelización y socialización; y la prensa como complemento para que los indígenas practiquen la lectura y la escritura, son rasgos que deben destacarse dentro de la difusión de los procesos de participación alcanzados con la escucha y el diálogo. La "Misión Radial", el 28 de marzo de 1965 se desarrolló en 246 asambleas comunitarias en casas parroquiales, templos, casas de feligreses, establecimientos educativos católicos y laicos, literal p) tabla 5. A partir de preguntas que se hacían a través de ERPE, los asambleístas reflexionaban y proponían soluciones frente a sus problemas, (Gavilanes, 1992).

El emblemático proyecto del vínculo de Proaño con los medios, fue la alfabetización de los indígenas y el sistema de teleducación que "devolvió la luz a quienes no podíamos ver", como decía la carta del indígena Miguel Guzmán, leída en el programa radial Hoy y mañana del 8 de junio de 1973, expresado en el literal o) de la tabla 5, fase difusión/participación. Y las entrevistas concedidas a periodistas de medios nacionales defendió el acceso a la tierra de los indígenas luego de la muerte de su amigo Lázaro Condo (1979)

\section{Conclusiones}

En base a los resultados discutidos de las 153 actividades, realizadas entre 1954 y 1988 , en las comunidades indígenas y en organizaciones sociales de Chimborazo se puede concluir:

- Los resultados respondieron la pregunta ¿de qué manera la investigación acción participativa de Proaño registró información sobre la realidad socio-cultural que sirvió para motivar la acción y cambio social de las comunidades indígenas de Chimborazo entre 1954 y 1988? Los datos registrados en el proceso: escucha/investigación, diálogo/ acción y difusión/participación, fueron desarrollados en momentos concretos como: la visita pastoral, asambleas comunitarias y encuentros con indígenas con organizaciones, y el uso de los medios masivos (prensa y radio). La IAP fue un instrumento de acercamiento, toma de información, interpretación y cambio social que para Canaval (2000, p. 37) el término "se aplica a una gran variedad de fenómenos y puede llegar a 
ser ambiguo o vago como resultado del uso convencional, amplio y variado".

- Se confirmó el objetivo: Identificar la utilización de la IAP en la diócesis de Riobamba para transformación social. La información obtenida está en concordancia con los objetivos de la investigación acción participación: generar cambios estructurales; obtener conocimiento interactivo y social desde la realidad; enfatizar que los participantes son el inicio y el fin de la transformación; las técnicas o instrumentos empleados por Proaño fueron la escucha, el diálogo y la difusión para los tres momentos de la IAP (como se dijo en el párrafo anterior), y consta en los documentos observados en el presente artículo.

- Las fases investigación acción participación configuraron momentos claves para la transformación. Están vinculadas con las preguntas utilizadas en los encuentros, los valores usados en los discursos que van desde el evangelio católico hasta lo éticoderechos humanos, y los actos de tipo comunicativo. En conjunto sirvieron para que el cambio no sea solo un sueño por cumplir, sino un hecho que se cosificó con el involucramiento de los participantes.

- El listado de interrogantes (tabla 3) fue utilizado en la fase de acción de la IAP. Sirvió para acumular datos provenientes del diálogo en asambleas comunitarias con indígenas y representantes de organizaciones sociales, y a partir de las respuestas se pasó a la siguiente fase (participación) para cosificarlas en proyectos concretos como la integración del indio a la vida civilizada.

- Los valores de la Biblia católica, al principio, y luego, los expresados en la Declaración de los Derechos del Hombre sirvieron para que el indígena alcance el cambio social; la comunicación sirvió para su conocimiento y les ubicaron en el mismo nivel que los mestizaos, desarrollando empatía e igualdad.

- Los actos comunicativos de las tres etapas: escucha, diálogo y difusión, le corresponden a cada una de las fases: investigación acción participación, en acciones con organizaciones propias como las audiencias en el despacho del obispo, las reuniones de las comunidades eclesiales de base o la construcción del proyecto para incorporar al indio a la vida civilizada.

- Observados los datos y efectuada su discusión se puede afirmar que existen semejanzas y paralelismos en la aplicación del método ver, juzgar y actuar, la teología de los signos y la investigación acción participativa; Leonidas Proaño fue pionero en el uso de la comunicación humana, biológica y tecnológica del momento (escucha-diálogo; radioprensa); esa combinación original de elementos y evolución del discurso, de los valores bíblicos a los valores de derechos humanos aplicados a las comunidades indígenas. Muestra una apertura al priorizar el pensamiento científico, de ver los denominadores comunes éticos de los valores para evitar las injusticias en las comunidades indígenas.

\section{Referencias}

- Alcantara, L.C.S, Sampaio, C.A.C. \& Uriarte, L. (2018): "Experiencia Cooperativa de Mondragón: la educación cooperativa como un proceso de transformación social", CIRIECEspaña, Revista de Economía Pública, Social y Cooperativa, 93, 181-209, DOI: 10.7203/ CIRIEC-E.93.9217. Fecha de consulta: 26-09-2018.

- $\quad$ Alfaro, R. (1993). Una comunicación para otro desarrollo, Fundación Calandria. Lima.

- Ávalos, B. (2017). Comunicación contrahegemónica, ventriloquía y lenguaje de contienda 
en Escuelas Radiofónicas Populares del Ecuador y Movimiento Indígena de Chimborazo 1960- 1990. (Tesis) Recuperado de http://repositorio.flacsoandes.edu.ec/xmlui/bitstream/ handle/10469/12441/TFLACSO-2017MBAT.pdf? sequence=2\&isAllowed=y).

- Bacher, C. (2016). Aportes de la investigación-acción participativa a una teología de los signos de los tiempos en América Latina. Theologica Xaveriana. Vol. 67 no. 184. jul.-dic. 2017. 309-332. Bogotá, Colombia. Issn 2011-219X.

- Bardin, L. (1986): El análisis de contenido. Madrid, Akal

- Baudrillard, J. (1984). Cultura y simulacro. Kairós. Barcelona

- Berelson, B. (1952): Content Analysis in Communication Researches. Glencoe III, Free Press.

- Canaval, G. (2000). El cambio social: análisis del concepto y aplicación en la investigación, educación y práctica de los profesionales de la salud. Colombia Médica, 31 (1), 37-42.

- Clauso, A. (1993). P uisía General dc Inflirinacián y Dtx,nnenta i6n, Vol. 3 (II, 11-19, Edil. Complutense. Madrid.

- $\quad$ Castillo, M. T., Viga M. D., \& Dickinson (2008). Changing the culture of dependency to allow for succesful outcomein participatory research: Fourteen years in experience in Yucatán, México. En P. Reason y H. Bradbury (eds.). The sage handbooks of action research, participatory inquiryand practice (pp. 522-523). Los Ángeles Sage.

- Corredor-Aristizábal, J. (2010). Revista Colombiana de Psicología. Vol. 19 n. 2 julio-diciembre 2010. issn 0121-5469. Bogotá, Colombia.

- Dubravcic, M. (2002). Comunicación Popular. Ediciones Abya Yala. Quito - Ecuador

- Freire, Paulo. 1976. Pedagogía del Oprimido. México: Siglo XXI Editores

- García, D. (2008). Por los caminos de la Educación Radiofónica. Universidad de Brasil

- Gavilanes, J. (1992). Monseñor Leonidas Proaño y su misión profético-liberadora en la iglesia de América Latina. FEPP. Quito - Ecuador.

- Gramsci, A. (1970). Introducción a la filosofía de la praxis. Barcelona: Península

- Guardiola, E. (2017). Convergencias de la investigación acción participativa y el pensamiento complejo. Investigación \& desarrollo vol. 25, nº 1 (2017) - issn 2011-7574 (on line). Fecha de consulta: 24 de octubre de 2017.

- Gómez, M,; Deslauriers, J.; y Piedrahita, M. (2010). Cómo hacer tesis de maestría y doctorado - investigación, escritura y publicación. Ecoe Ediciones. Bogotá

- Herrera M. Environmentalism and political participation: toward a new system of social beliefs and values. J Appl Social Psychol 1992; 22: 657-76.

- Huergo, Jorge A., Nuevas aventuras de la perspectiva crítica: la investigación "con" la transformación social. Nómadas (Col) [en linea] 2002, (Sin mes) : [Fecha de consulta: 24 de octubre de 2018] Disponible en http:// www.redalyc.org/articulo.oa?id=105117951004 ISSN 0121-7550

- Igartúa, J. \& Humanes, M. (2010). Teoría e Investigación en Comunicación Social. Editorial Síntesis. Madrid - España.

- Kaplún, M. (1983). Comunicación popular ¿alternativa válida? Revista Chasqui Vol. 7. Quito - Ecuador.

- Kemmis, R. \& Mc Taggart, R. (2005). Participatory Action Research. Comunicative action and the public sphere. En N. Denzin y Y. Lincoln (eds.). The sage handbooks of qualitative research (pp. 559-603). Londres: Sage.

- $\quad$ Kirk, J. \& Miller, M. (1986), Reliabilitv !Illd \ialidily in Qualitative Research, New Park: California: Sage, Qualitative Research Methods Series.

- $\quad$ Kvale, S. (1961). Imerviews. All trodllc to qllalitalive research tervieving, Londres: Sage.

- López, F. (2002): El análisis de contenido como método de investigación. Revista de Educación, 4 (2002): 167-179. Universidad de Huelva. 
- Máiz, R. (2004). Revista de Estudios Políticos (Nueva Época) Núm. 123. Enero-marzo 2004. México.

- Marcuse, H. Über konkrete Philosophie. Frankfurt am Main, Europäische Verlagsanstalt, 1973. Y en: "Schriften". Vers. cit. 1987. Un análisis bastante interesante en: Spiro, L.: "The FreudoMarxism of Herbert Marcuse". Columbia University Press, 1973.

- Mills, C. W. (1959), The sociological imagination, Nueva York: The Oxford University Press.

- Monje, C. (2011). Metodología de la investigación cualitativa y cuantitativa. Universidad SurColombiana. Neiva.

- Muñoz, M. (2011). A propósito de La Dialéctica Concreta de Herbert Marcuse. Universidad Carlos III de Madrid, Madrid, España.

- $\quad$ ONU (1954). El Desarrollo Económico del Ecuador. Estudio realizado por la Secretaría de la Comisión Económica para América Latina - CEPAL (Reedición). México.

- Ossandon, F (1988). Comunicación popular, alternativa y participatoria. Ediciones Ciespal. Quito - Ecuador.

- Park, P. (2011). Qué es la investigación acción participativa. Perspectivas teóricas y metodológicas. En La investigación acción participativa. Inicios y desarrollos, Editado por María Cristiana Salazar, 135-174. Bogotá: Magisterio.

- Pellegrino, L. (2017). Las historias de vida en el método de planificación pastoral ver-juzgaractuar. Veritas, № 36 (Abril 2017). Italia.

- Proaño, L. (1956). De conversación con mis hijos - la parcelación. Revista Mensaje (Diócesis de Riobamba), p. 8.

- Proaño, L. (1959). De conversación con mis hijos - Horizontes. Revista Mensaje (Diócesis de Riobamba). pp.176-178.

- Proaño, L. (1960). De conversación con mis hijos - El CEAS. Revista Mensaje (Diócesis de Riobamba). pp. 81-82.

- Proaño, L. (1974). Concientización, evangelización y política. Ediciones Sígueme. Salamanca - España.

- Proaño, L. (1976). Evangelio Subversivo. Ediciones Sígueme. Salamanca - España.

- Proaño, L. (2011). Abriendo surcos indígenas 1. Fondo Documental Diocesano. Riobamba, Ecuador.

- Proaño, L. (2011). Abriendo surcos indígenas 1. Fondo Documental Diocesano. Riobamba, Ecuador.

- Rizo García, Marta, Comunicación e interacción social. Aportes de la comunicología al estudio de la ciudad, la identidad y la inmigración. Global Media Journal [en linea] 2004, 1 (otoño): [Fecha de consulta: 23 de julio de 2018] Disponible en: $\leq$ http://www.redalyc.org/articulo. oa? id $=68710210>$ ISSN 2007-2031

- Rizo, M. (2012). Imaginarios sobre la comunicación. Algunas certezas y muchas incertidumbres en torno a los estudios de comunicación, hoy. Bellaterra: Institut de la Comunicació, Universitat Autònoma de Barcelona. ISBN 978-84-939674-6-8

- Rojas, R. (2012). Investigación - acción - participativa. Universidad Politécnica Salesiana.

- Saldívar, E. (2003). Indigenismo Legal: la política indigenista de los noventas.Revista Mexicana de Ciencias Políticas y Sociales, XLVI (189), 311-339.

- Sanz, F. (2001). La Juventud Obrera Cristiana: Un movimiento educativo popular. Ediciones Universidad de Salamanca. Hist, educ. y 20, 2001, pp. 95-115. Fecha de consulta: 24-09-2018

- Selener, D. (1997). Participatory action research and social change. NY: Cornell University Participatory Action Research Network. Fecha de consulta: 24-09-2018

- Serrano, M. (1982). Teoría de la Comunicación. Gráficas Valencia. Madrid - España

- Silva, E. (2009). Una teología de los signos de los tiempos latinoamericanos. Validez, límites y porvenir de una hermenéutica teológica del Concilio. Teología y Vida, L (1-2), 41-58.

- Singer, M. (2011). ¿Exclusión o inclusión indígena? Universidad Nacional Autónoma de México, 
Facultad de Ciencias Políticas y Sociales, Centro de Estudios Políticos. Estudios Políticos núm. 31 (enero-abril, 2014): 87-106. México, D.F. ISSN: 0185-1616. Fecha de consulta: 24-09-2018

- Stavenhagen, Rodolfo (2001), "El derecho de sobrevivencia: la lucha de los pueblos indígenas en América Latina contra el racismo y la discriminación", Santiago de Chile, Comisión Económica para América Latina y el Caribe, Instituto Interamericano de Derechos Humanos, Reunión de Expertas sobre Racismo y Género, 4 y 5 de junio. Fecha de consulta: 24-09-2018.

- $\quad$ Urdapilleta \& Llilmón (2018). Revista Colombiana de Sociología. Vol. 47 No. 1. Enero - junio 2018. Bogotá, Colombia.

- Vélez, C. (2016). "El quehacer teológico y el método de investigación acción participativa. Una reflexión metodológica". Theologica Xaveriana 183 (2017):187-208. https://doi.org/10.11144/ javeriana, tx67-183.qtmiap. Fecha de consulta: 25-09-2018

- Wals, A. (2007). Social learnig towards a sustainable world. Holanda: Wageningen Academics.

\section{CURRICULUM VITAE}

\section{Julio Bravo Mancero}

Julio Bravo Mancero, Doctor (c) en Comunicación e Información Contemporánea de la Universidad Santiago de Compostela; Magíster en Comunicación Corporativa por la Universidad Regional Autónoma de los Andes (2014). Profesor Titular en la Carrera de Comunicación Social de la Universidad Nacional de Chimborazo. Ha publicado los libros: Memorias de la pelota (2006), Reflexiones sobre Comunicación (2009), Palabra Escrita (2010), La rosa de los vientos (2011). Ha sido Director, Editor y Jefe de Redacción de Diario Regional Los Andes, Riobamba. Editor de la Sección B, Diario La Prensa, Riobamba; Director de Relaciones Públicas y Director de Carrera de CS, Unach.

\section{Jorge Mora Fernández}

Doctor PhD. Docente de la Universidad Nacional de Chimborazo. Researcher Affiliated at Arthur C. Clarke Center for Human Imagination, UCSD, University of California San Diego. http://imagination. ucsd.edu/index.html\#people - Co-Director of the Research Group CICNETART I+D+C, www.cicnetart.org Co-Director of the Research Group NEUROSYNAPSIS,

\section{Fermín Galindo Arranz}

Doctor en Ciencias de la Información por la Universidad del País Vasco (1992) y Profesor Titular de Periodismo de la Universidad de Santiago de Compostela. Ha publicado: Fundamentos de Comunicación Política (1998), A Comunicación Política Hoxe (1999), Ámbitos del Periodismo de Precisión (2004) y Las notas de la prensa (2010) y Siete Picas. Entre la Ciencia y el Periodismo (2016). 